\title{
Ionospheric response to total solar eclipse of 22 July 2009 in different Indian regions
}

\author{
S. Kumar ${ }^{1, *}$, A. K. Singh ${ }^{2}$, and R. P. Singh ${ }^{2}$ \\ ${ }^{1}$ Aryabhatta Research Institute of Observational Sciences (ARIES), Manora Peak, Nainital, India \\ ${ }^{2}$ Atmospheric Research Lab., Department of Physics, Banaras Hindu University, Varanasi-221005, India \\ *currently at: School of Electrical and Electronic Engineering (EEE), Nanyang Technological University (NTU), \\ Singapore-639815, Singapore
}

Correspondence to: A. K. Singh (abhay_s@ rediffmail.com)

Received: 7 April 2013 - Revised: 25 July 2013 - Accepted: 26 July 2013 - Published: 9 September 2013

\begin{abstract}
The variability of ionospheric response to the total solar eclipse of 22 July 2009 has been studied analyzing the GPS data recorded at the four Indian low-latitude stations Varanasi (100\% obscuration), Kanpur (95\% obscuration), Hyderabad (84\% obscuration) and Bangalore (72\% obscuration). The retrieved ionospheric vertical total electron content (VTEC) shows a significant reduction (reflected by all PRNs (satellites) at all stations) with a maximum of $48 \%$ at Varanasi (PRN 14), which decreases to $30 \%$ at Bangalore (PRN 14). Data from PRN 31 show a maximum of $54 \%$ at Kanpur and $26 \%$ at Hyderabad. The maximum decrement in VTEC occurs some time (2-15 min) after the maximum obscuration. The reduction in VTEC compared to the quiet mean VTEC depends on latitude as well as longitude, which also depends on the location of the satellite with respect to the solar eclipse path. The amount of reduction in VTEC decreases as the present obscuration decreases, which is directly related to the electron production by the photoionization process. The analysis of electron density height profile derived from the COSMIC (Constellation Observing System for Meteorology, Ionosphere \& Climate) satellite over the Indian region shows significant reduction from $100 \mathrm{~km}$ altitude up to $800 \mathrm{~km}$ altitude with a maximum of $48 \%$ at $360 \mathrm{~km}$ altitude. The oscillatory nature in total electron content data at all stations is observed with different wave periods lying between 40 and $120 \mathrm{~min}$, which are attributed to gravity wave effects generated in the lower atmosphere during the total solar eclipse.
\end{abstract}

Keywords. Radio science (ionospheric physics)

\section{Introduction}

The Moon comes between the Earth and the Sun regularly every 223 lunar revolutions, which results in solar eclipse and obscures the solar flux reaching the Earth's surface. The occultation of the solar disk arises due to the fact that the apparent diameters of the Sun and the Moon as viewed from the surface of the Earth are equal. The partial/total termination of the solar flux affects chemical reactions, production and transport of ionization in the ionosphere (Sharma et al., 2010; Galav et al., 2010; Kumar and Singh, 2012), boundary layer phenomena (Jayakrishnan et al., 2013), ozone production, loss and columnar concentration (Chakrabarty et al., 1997; Kumar and Rengaiyan, 2011) and many other related phenomena including the generation and propagation of gravity waves (Farges et al., 2003). Since an eclipse generally occurs at different times of the day in different seasons at different places (varied in latitudes and longitudes) on the globe, it provides unique opportunity to test the proposed hypothesis and to verify the earlier results.

Measurements showed dramatic reduction in magnitude of the incoming solar radiation at all sites after the first contact, which is proportional to the eclipse magnitude (Founda et al., 2007). Eclipse-induced changes in the spectral solar irradiance at the Earth's surface have also been observed (Zerefos et al., 2000). As a result photoionization activity in the ionosphere during the eclipse period decreases to almost nighttime conditions. The changes in the electron density distribution and the total electron content (TEC) have been studied using different techniques such as the Faraday rotation measurements (Tyagi et al., 1980; DasGupta et al., 1981), 
ionosonde networks (Venkatesh et al., 2011), incoherent scatter radars (Zhang et al., 2004), GPS systems (Ramarao et al., 2006) and satellite measurements (Davies and Hartmann, 1997). GPS systems provide data with better accuracy both in time and space and hence are widely used in ground-based studies (Bagiya et al., 2011; Kumar and Singh, 2011; Galav et al., 2011).

The ionospheric response to solar eclipse is quite complex, and it varies from eclipse to eclipse in addition to the altitude and latitude variations. Usually a large amount of decrease in the electron density at lower altitudes (below F1 layer) is observed (Salah et al., 1986; Le et al., 2008), whereas in the F2 region altitude, an increase (Evans, 1965; Salah et al., 1986; Le et al., 2010) and decrease (Le et al., 2010; Jakowski et al., 2008) in the electron density are reported. The different behavior of F2 layer arises due to the fact that the electron density is more controlled by the transport process than by the production rate. Observations combined with modeling showed the F2 layer behavior to depend on the local time, solar activity, background neutral gas concentration and dip angle (Le et al., 2008). However, a decrease in TEC during solar eclipse is observed, which is dependent on latitude and local time (Le et al., 2010). The latitudinal variation may arise due to the latitudinal variation of magnetic inclination angle, which influences plasma diffusion (Ding et al., 2010). The dependence on local time is attributed to the rate of electron loss, which is related to the local-timedependent background density. Afraimovich et al. (1998), analyzing the GPS data corresponding to the solar eclipse of 9 March 1997 collected at different locations within $52 \pm 6^{\circ} \mathrm{N}$ and $104 \pm 11^{\circ} \mathrm{E}$, showed that the decrease in TEC is nearly independent of latitude and longitude. The TEC decrement during the 3 October 2005 eclipse over European latitudes and longitudes is found to depend on the observation site (Krankowski et al., 2008). For the same eclipse, Jakowski et al. (2008) showed $\sim 30 \%$ reduction in TEC, presence of gravity waves of $\sim 60 \mathrm{~min}$ wave period, and an enhancement of slab thickness by $\sim 20 \mathrm{~km}$ during the initial phase of the eclipse. They also reported that the ionospheric response to the obscuration function is delayed by $20-30 \mathrm{~min}$, which increased with altitude. The increased delay with altitude can be understood in terms of altitude dependence of plasma processes. At the lower altitude strong recombination processes are faster than the diffusion process at higher altitudes, which need some time to come into effect.

The impact of solar eclipse in the low-latitude/equatorial region is difficult to predict because of the presence of equatorial electrojet (EEJ) and the equatorial ionospheric anomaly (EIA). Tomás et al. (2007) have shown that an eclipse can trigger a reversal in the EEJ (also termed counterelectrojet CEJ). St-Maurice et al. (2011) have proposed that traveling low pressure centers associated with the center of the eclipse may reverse the local wind pattern and trigger a CEJ. During the normal EEJ condition, the zonal electric field is eastward and lifts the plasma upwards. In
CEJ condition, the plasma moves downward. Choudhary et al. (2011) analyzed GPS data recorded over a chain of stations spread in latitudes and showed that the eclipse (15 January 2010) influenced the electron density over a much wider region than that expected from the obscuration factor alone. The local magnetometer data revealed the presence of CEJ. Sridharan et al. (2002), using data from the ground-based ionosondes, VHF and HF radars, have studied the effect of dusk time total solar eclipse (11 August 1999) on the electrodynamical processes of the equatorial ionosphere. They have reported sudden intensification of a weak blanketing Es layer, a significant increase in the $\mathrm{F}$ region base height immediately following the eclipse and distinctly different spatial and temporal structures in the spread $\mathrm{F}$ irregularities.

Another interesting effect of solar eclipse is the observation of gravity waves during solar eclipses (Zerefos et al., 2007; Paul et al., 2011). Chimonas and Hines (1970) suggested for the first time that the Moon's shadow moving with supersonic velocity may disturb the heat balance along the trajectory leading to the gravity wave generation during solar eclipse. The sources of gravity waves were proposed to be the thermosphere where molecular oxygen heating begins (Chimonas, 1970), the stratosphere where ozone layer heating takes place (Fritts and Luo, 1993; Zerefos et al., 2000) and the troposphere where water vapor IR absorption and ground cooling occurs (Chimonas and Hines, 1971; Chimonas, 1973). Modeling studies supported the idea of eclipse-induced gravity wave generation in the thermosphere (Ridley et al., 1984; Roble et al., 1986; Muller-Wodarg et al., 1998), which is also supported by measurements (Liu et al., 1998; Altadill et al., 2001; Sauli et al., 2006). Zerefos et al. (2007) reported waves with periods ranging from 30 to $40 \mathrm{~min}$ associated with thermal stratospheric ozone forcing. Singh et al. (1989) have reported waves with a period of 10-40 min measured at more than $50 \mathrm{~km}$ from the zone of totality. Paul et al. (2011) reported wave-like structures in the GPS TEC data at Calcutta, Kharagpur and Baharampur located outside the umbra zone in the Indian longitude sector of the solar eclipses of 22 July 2009 and 15 January 2010.

The depletion in GPS TEC data during the solar eclipse varies from station to station situated at different latitudes and longitudes and depends on many factors. Even the presence or absence of wave-like structures varies from eclipse to eclipse and the location of the observation site. In order to understand some aspect of these problems, we have analyzed GPS TEC data recorded at the four Indian stations Varanasi (situated at the edge of the EIA), Kanpur, Hyderabad and Bangalore located in the longitude sector $77-83^{\circ} \mathrm{E}$ and the latitude sector $13-26^{\circ} \mathrm{N}$ during the solar eclipse of 22 July 2009 . The vertical electron density profile derived from the analysis of COSMIC satellite data for the Indian region is also presented. The reduction in vertical total electron content (VTEC) compared to quiet mean VTEC at Varanasi is found to be less than that observed at Kanpur, although Varanasi lies in the total obscuration path, whereas Kanpur 
lies just outside the total obscuration path. This may be due to the effect of EIA. As the observation station moves away from the totality path, the depletion in VTEC decreases. This is evident from the present observations. The Fourier analysis of TEC data shows the presence of wave-like structures having periodicity of $\sim 20-40 \mathrm{~min}$ for Varanasi, $40-60 \mathrm{~min}$ for Kanpur, 90-110 min for Hyderabad and 60-90 min for Bangalore data, which are attributed to the eclipse-induced cooling.

\section{Total electron content (TEC) measurements}

The ionospheric variability can be studied using the temporal evolution of total electron content, which is derived from either carrier phase measurements or pseudo-range measurements. The GPS receiver Trimble 5700 and Zephyr Geodetic antenna (Rover configuration) are used for the data collection. The system can simultaneously record dual frequency signals from 12 satellites. Using the software, the data recorded in RINEX (Receiver Independent Exchange) format are converted into the slant total electron content (STEC) along the path of the signal propagation from the satellite to the receiver, which is converted again into the vertical total electron content (VTEC) using the simple procedure discussed elsewhere (Mannucci et al., 1993; Langley et al., 2002; Ramarao et al., 2006; Kumar and Singh, 2011).

The locations of the four Indian stations Varanasi (geog. lat. $25^{\circ} 16^{\prime} \mathrm{N}$, long. $82^{\circ} 59^{\prime} \mathrm{E}$ ), Kanpur (geog. lat. $26.28^{\circ} \mathrm{N}$ and long. $80.2^{\circ} \mathrm{E}$ ), Hyderabad (geog. lat. $17^{\circ} 20^{\prime} \mathrm{N}$, long. $78^{\circ} 30^{\prime} \mathrm{E}$ ) and Bangalore (geog. lat. $12^{\circ} 58^{\prime} \mathrm{N}$, long. $77^{\circ} 33^{\prime} \mathrm{E}$ ), along with the path of the maximum obscuration and the path of the satellite designated by PRN 14 and 31, are shown in Fig. 1. PRN 14 and 31 specify the chosen GPS satellites for which data are available at all four stations. The Varanasi station lies inside the total obscurity zone, whereas Kanpur lies near but outside the total obscurity zone. The Bangalore station is at the largest distance from the obscurity zone but lies closer to the Equator. Both Bangalore and Hyderabad are inside the equatorial anomaly region, whereas Varanasi lies at the edge of EIA zone. The eclipse time and percent obscuration at different stations are given in Table 1. The eclipse occurred during the local morning hours and continued for about $2 \mathrm{~h}$. On the day of eclipse, sky was cloud-free and clear with no rainfall. However, a geomagnetic storm is reported on 22 July 2009. The magnetometer data from Indian stations reveal the storm-related changes in the ground magnetic field after 04:00 UT (09:30 LT). As the solar eclipse occurred before the magnetic storm, we safely assume that the results presented in this paper are unaffected by the magnetic storm before 09:30 LT, whereas after the 09:30 LT data may be affected by the magnetic storm.

The data from Kanpur are obtained under the exchange program, whereas the data for Hyderabad and Bangalore stations in compact RINEX FORMAT are downloaded from

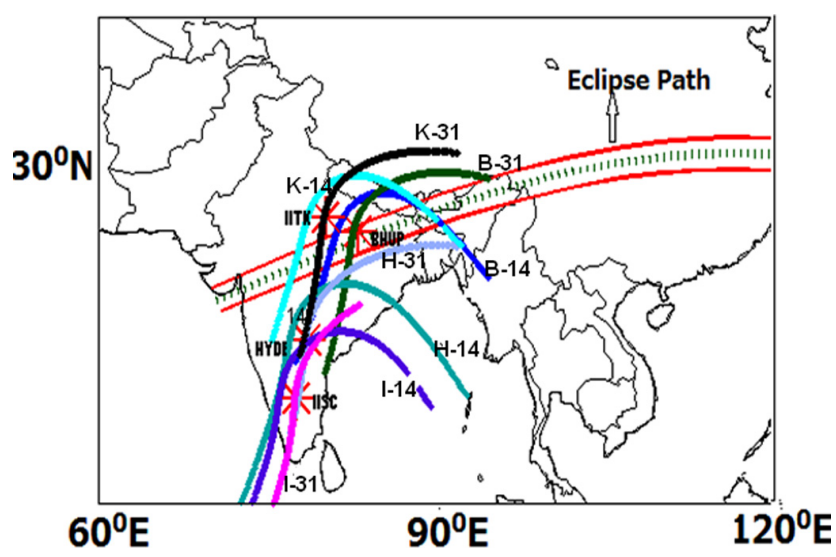

Fig. 1. Map showing the path of maximum obscuration for total solar eclipse of 22 July 2009, location of the stations in the Indian region, paths of the satellites designated by PRN 14 and 31. "K" stands for Kanpur, "B" for Varanasi, "H" for Hyderabad and "I" for IISc Bangalore.

the International GNSS Service (IGS) website. We have also studied the percentage changes in VTEC (\% DVTEC), which is obtained using the relation

$\%$ DVTEC $=\frac{(\text { Eclipse day VTEC }- \text { Background VTEC })}{\text { Background VTEC }} \times 100$.

The background VTEC for the reference is obtained by averaging the VTEC values of 17, 18, 19, 20, 27, 28, and 31 July. These days are considered based on the consideration of a few days before and after the eclipse during the quiet period. From 22 July to 26 July, there was a magnetic storm.

In order to substantiate and confirm the TEC data from GPS measurements, the electron density profile measured from COSMIC mission during the eclipse period and the average electron density profile obtained from the available data before and after the eclipse day are analyzed. The COSMIC mission data are stored at the University Corporation for Atmospheric Research in Boulder, USA, and data are downloaded from the website http://www.cosmic.ucar.edu.

\section{Results}

Figure $2 \mathrm{a}$ shows the variation of vertical total electron content with time in TEC unit $\left(1\right.$ TEC unit $=10^{16}$ electrons $\left.\mathrm{m}^{-2}\right)$ recorded at Varanasi from PRN 14 and 31. In the same figure the average VTEC derived from the same PRN is also plotted. The day-to-day variability is represented by $1 \sigma$ vertical bar. In the bottom panel percentage deviation from the average value is also shown. The deviation in VTEC varies with time showing a dip at around 06:30 LT. The vertical total electron content goes on decreasing with time, and after 06:30 LT the same starts recovering. There is a faster rate of recovery initially (up to 07:40LT for PRN 14 and 07:30 LT for PRN 31), and then the rate of recovery is slowed 
Table 1. Local circumstances for total solar eclipse on 22 July 2009 at all four locations.

\begin{tabular}{lcccccc}
\hline Station & Geog. latitude & Geog. longitude & Start of partial eclipse & $\begin{array}{c}\text { Maximum } \\
\text { eclipse }\end{array}$ & $\begin{array}{c}\text { End of minimum } \\
\text { eclipse }\end{array}$ & $\begin{array}{c}\text { Maximum obscuration } \\
\text { rate }(\%)\end{array}$ \\
\hline Varanasi & $25^{\circ} 16^{\prime} \mathrm{N}$ & $82^{\circ} 59^{\prime} \mathrm{E}$ & $00: 00 \mathrm{UT}$ & $00: 55 \mathrm{UT}$ & $01: 57 \mathrm{UT}$ & 100 \\
Kanpur & $26^{\circ} 18^{\prime} \mathrm{N}$ & $80^{\circ} 12^{\prime} \mathrm{E}$ & $00: 01 \mathrm{UT}$ & $00: 55 \mathrm{UT}$ & $01: 56 \mathrm{UT}$ & 95 \\
Hyderabad & $17^{\circ} 20^{\prime} \mathrm{N}$ & $78^{\circ} 30^{\prime} \mathrm{E}$ & $23: 58 \mathrm{UT}$ on $21 \mathrm{July}$ & $00: 52 \mathrm{UT}$ & $01: 50 \mathrm{UT}$ & 84 \\
Bangalore & $12^{\circ} 58^{\prime} \mathrm{N}$ & $77^{\circ} 33^{\prime} \mathrm{E}$ & $23: 59 \mathrm{UT}$ & $00: 51 \mathrm{UT}$ & $01: 47 \mathrm{UT}$ & 72 \\
\hline
\end{tabular}
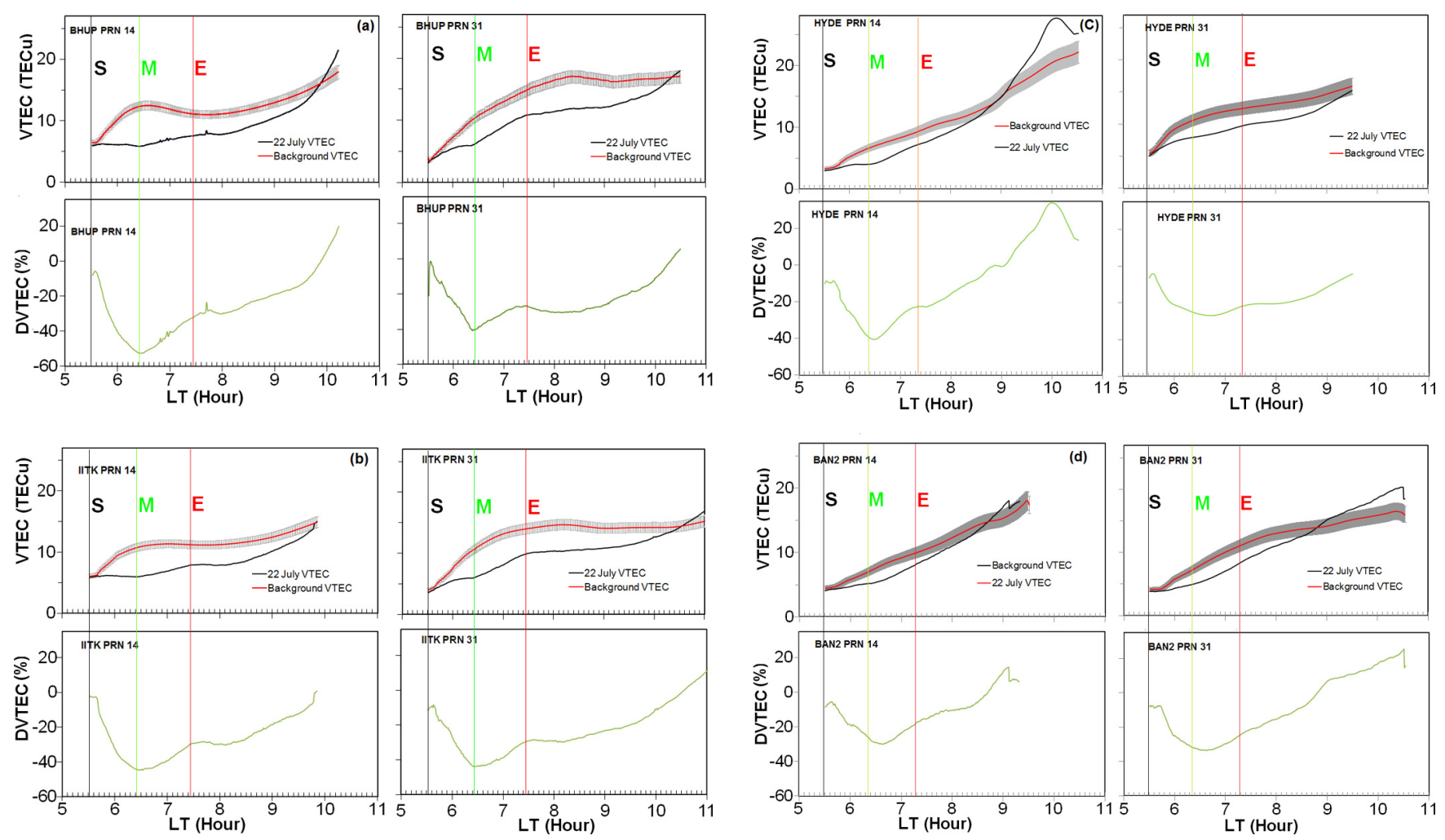

Fig. 2. Variation of VTEC compared to quiet mean VTEC and percentage change in VTEC compared to quiet mean VTEC (DVTEC) estimated from PRNs 14 and 31 data during total solar eclipse period at (a) Varanasi (BHUP), (b) Kanpur (IITK), (c) Hyderabad (HYDE) and (d) Bangalore (IISc).

down. The rate of recovery is accelerated after 09:30 LT for both PRNs. After 10:00 LT VTEC exceeds the average value (for PRN 14), whereas the same trend is observed after 10:30 LT for PRN 31. After 09:30 LT, there may be the effect of geomagnetic storm. Therefore, we would restrict them to 09:30 LT or before. The eclipse starts at 05:30 LT and reaches $100 \%$ obscuration at 06:25. Thus the decrease in VTEC exactly follows the eclipse evolution. As the percent obscuration goes on decreasing, VTEC starts recovering due to production of photoionization by partial solar radiation falling into the atmosphere. At the 07:27 LT solar eclipse terminates and normal solar radiation falls on the atmosphere and normal photoionization begins. It takes about $2.5 \mathrm{~h}$ for the VTEC to reach the normal value. The maximum decrease in VTEC is $\sim 51 \%$ for PRN 14 and $\sim 41 \%$ for PRN 31 . The larger change in VTEC corresponding to PRN 14 may be because the path of satellite signal passes through the obscurity zone for a larger distance than that from PRN 31.

The VTEC and the average value of VTEC derived from the same PRNs 14 and 31 observed at IIT Kanpur station are shown in Fig. 2b. The eclipse starts at 05:31 LT and continues for $1 \mathrm{~h}$ and $56 \mathrm{~min}$, with the maximum obscuration of $95 \%$ at 06:25 LT. PRN 14 shows almost the same value as the average value, whereas PRN 31 yields slightly a smaller value than the average value at the start of the eclipse, although the value is within the error bar. Therefore, the small reduction before the starting time of the eclipse is artificial. Initially the magnitude of DVTEC for both PRNs increases, shows a dip 

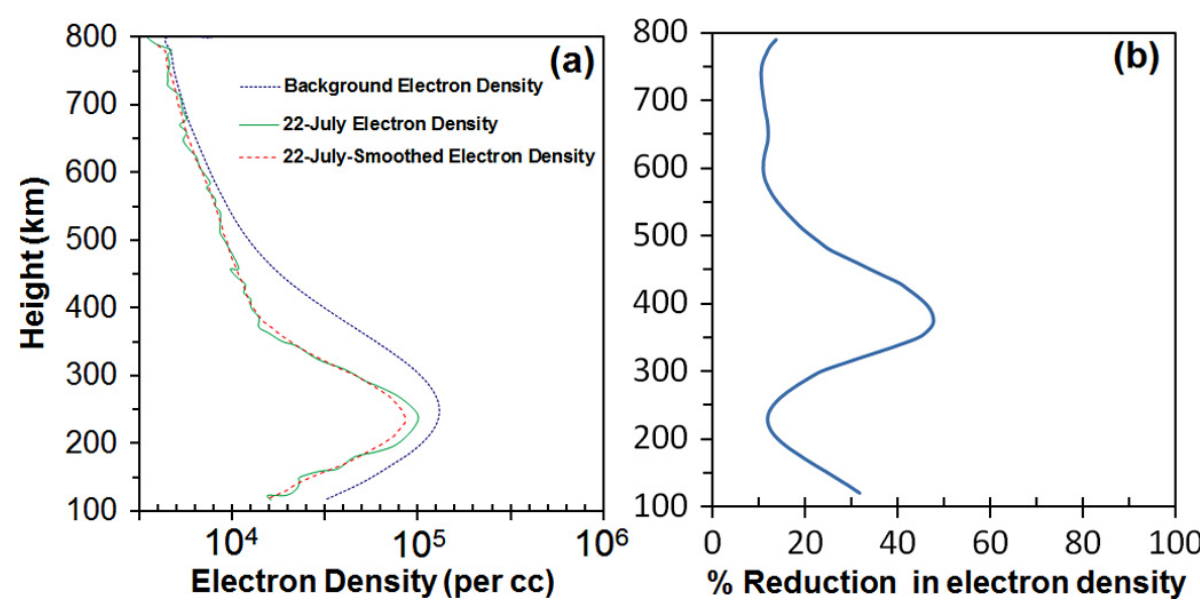

Fig. 3. (a) Variation of electron density profiles obtained from the FORMOSAT-3/COSMIC GPS-RO satellites over Indian zone for the eclipse day (22 July 2009) and the mean during quiet day. The smoothed electron density profile on the eclipse day (running mean) is also shown and (b) the percentage change in electron density compared to smoothed electron density profile of quiet mean value between 06:30 and 07:30 LT over the Indian region.

at around 06:30 LT and then decreases. This shows that after the time of the maximum observation, VTEC starts recovering. For about $1 \mathrm{~h}$ after the termination of the eclipse, the DVTEC remains almost constant and thereafter decreases. VTEC derived from PRN 14 regains a normal value at around 10:00 LT. However, data from PRN 31 show that a normal value of VTEC is reached at 10:30 LT. The maximum reduction is $43 \%$ for PRN 31 and $45 \%$ for PRN 14. Again this difference may be attributed to the satellite position and the location of observation site.

The VTEC and DVTEC for PRNs 14 and 31 are given in Fig. $2 \mathrm{c}$ for the Hyderabad station, which had the maximum obscuration of $84 \%$. The maximum reduction in VTEC as measured by PRN 14 comes out to be $41 \%$ at the time of maximum obscuration. After that the recovery in VTEC is seen. PRN 31 shows a peculiar variation in DVTEC. The rate of change in DVTEC is initially quite large, and after 24 min from the start of eclipse, the rate of change of DVTEC slows down. The maximum reduction in VTEC comes out to be $\sim 27 \%$ at $06: 42 \mathrm{LT}$, about $18 \mathrm{~min}$ after the maximum obscuration. The maximum reduction in VTEC is observed by PRN 14 at around 06:30 LT, almost 8 min after the maximum eclipse obscuration. The time delay in the maximum deviation in VTEC may be due to some plasma dynamic phenomena.

Figure 2d shows the temporal evolution of VTEC and DVTEC recorded at the Bangalore station for PRNs 14 and 31. The maximum decrease in VTEC is observed after some delay from the maximum obscuration time (06:21 LT). The maximum decrease in VTEC is $\sim 31 \%$ for PRN 14 and $\sim 33 \%$ for PRN 31 . The observed time delay is 18 and 15 min for PRNs 14 and 31 respectively. Interestingly, the increase and decrease in magnitude of DVTEC for PRN 31 are almost identical both at the Hyderabad and Bangalore.
The vertical electron density profile derived from constellation of FORMOSAT-3/COSMIC satellite on 22 July 2009 between 06:30 LT and 07:30 LT is shown in Fig. 3a. The average electron density profile obtained by averaging the data for 17 and 29 July is also shown in the same figure for the Indian zone in the longitude sector $78 \pm 4^{\circ} \mathrm{E}$. We could get only two days near the eclipse events when the COSMIC satellite passes over the same location during the time interval of 06:30-07:30 LT. The profile corresponds to a time that is about $30 \mathrm{~min}$ past after its maximum obscuration of $75 \%$ at the F2 peak coordinates. To compute the better estimation of reduction in electron density, we have smoothed the COSMIC electron density profile on the eclipse day (running mean), which is also shown in Fig. 3a, and then computed the reduction. The reduction in electron density at all altitudes is seen. The height profile of percent reduction in electron density is shown in Fig. 3b, which shows a broad peak between 200 and $500 \mathrm{~km}$ altitudes with a maximum of about $48 \%$ at an altitude of $360 \mathrm{~km}$. The decrease in electron density reaches $\sim 10 \%$ at $\sim 250 \mathrm{~km}$ altitude and above $600 \mathrm{~km}$ altitude also.

Apart from the reduction in the electron density during the eclipse period, the hypothesis of gravity wave generation due to disturbance of heat balance along the trajectory of the shadow of the Moon has been proposed (Chimonas and Hines, 1970; Zerefos et al., 2007). In order to find out the presence/absence of oscillatory signature in the VTEC data, the mean VTEC is obtained by averaging data from all available PRNs during the eclipse period (Fig. 4a). In the same figure, we have also shown the best-fit polynomial for the data. Subtracting the smoothed data from the original VTEC of the eclipse period, the difference in TEC (DTEC) is also plotted in the same figure, which exhibits a clear oscillatory nature. Fourier analysis of time series data DTEC 

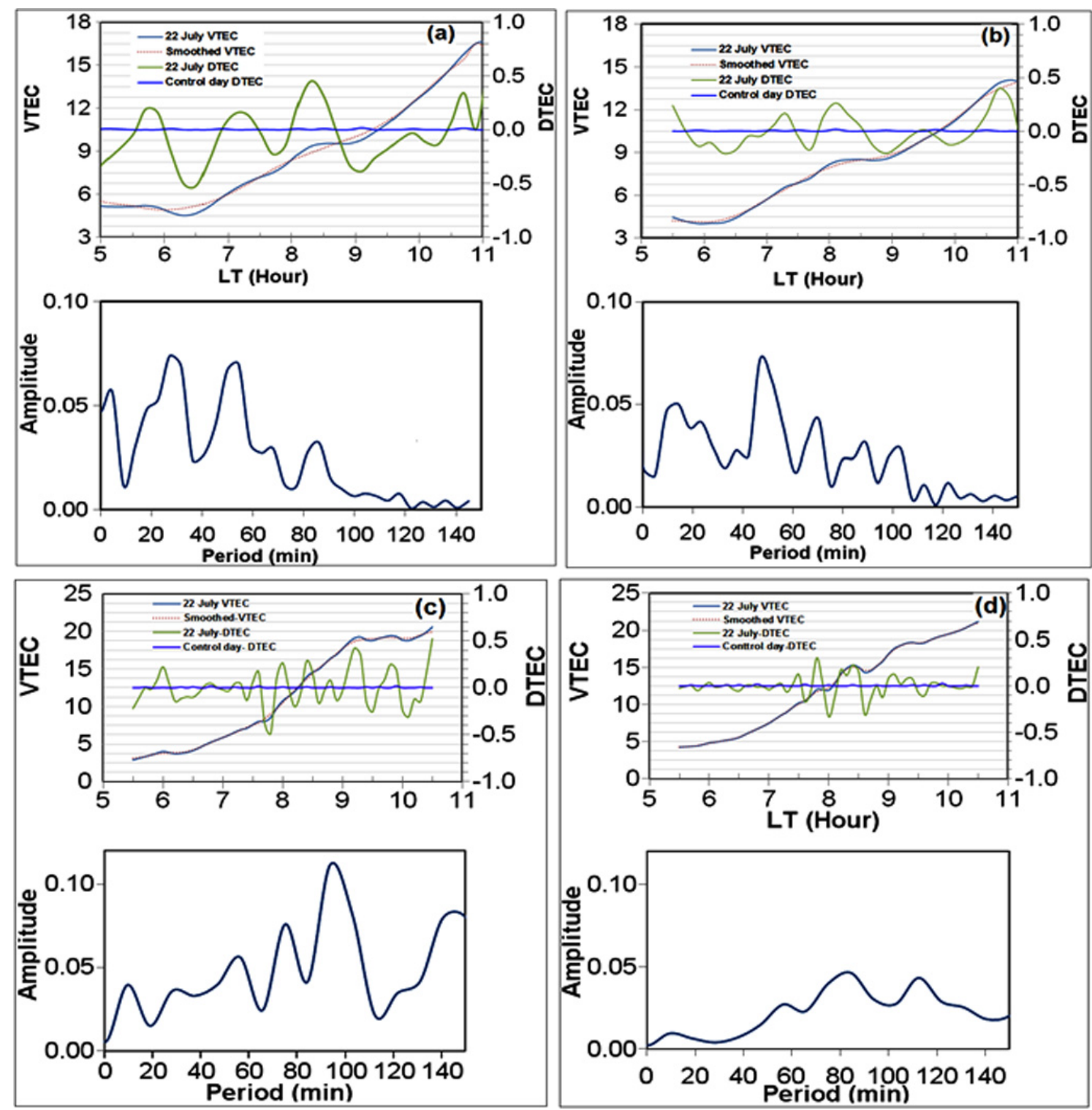

Fig. 4. Variation of VTEC, smoothed TEC (best polynomial fit to VTEC curve) and DTEC curve obtained by subtracting best polynomial fit to the original VTEC. Bottom panel shows the Fourier analysis of DTEC. (a) Varanasi, (b) Kanpur, (c) Hyderabad and (d) Bangalore.

is shown in the bottom panel of the figure. Power peaks for waves having periods between 20 and $40 \mathrm{~min}$ and between 40 and $60 \mathrm{~min}$. Similar analysis is carried out for the VTEC data obtained from the Kanpur station, and results are shown in Fig. 4b. In this case it is clearly seen that the maximum power corresponds to the wave with a wave period lying between 40 and $60 \mathrm{~min}$. We also performed a similar analysis for the VTEC data obtained for the Hyderabad and Bangalore, and the results are shown in Figs. $4 \mathrm{c}$ and d respectively. The Hyderabad data show wave periods in the range between 80 and 110 min have maximum power, whereas the presence of a wavy structure in the Bangalore data with periods 70 100 and 100-120 min could be seen. In this eclipse case the data clearly show the presence of wavy structures at all four stations lying in the obscuration zone of the eclipse. In order to support our argument that the wavy structures present in DTEC are due to the solar eclipse, we considered quiet and non-eclipse day (control day) VTEC data, and a similar DTEC analysis is also carried out. The result is also shown in Fig. 4. For significant oscillation amplitude of DTEC should be greater than $0.1 \mathrm{TECU}$, but on the control day DTEC amplitude is much less than 0.1 TECU. It is also clearly seen that the DTEC curve of control day at all four stations does not show any wave signatures. Thus the oscillation in DTEC curve observed at all four stations on 22 July is supposed to be due to the eclipse-induced gravity waves in the lower atmosphere. 


\section{Discussions}

The present study shows a reduction in VTEC compared to quiet mean VTEC at all four stations Varanasi, Kanpur, Hyderabad and Bangalore. The amount of reduction depends on the location of the recording station as well as the relative location of satellite path compared to the eclipse obscuration path. The time of the maximum decrease also depends on the location of the observing station. There is maximum reduction in VTEC at Varanasi and Kanpur stations for PRN 14 at around 06:30 IST (India Standard Time) (i.e., after about $5 \mathrm{~min}$ from the maximum obscuration and $1 \mathrm{~h}$ from the beginning of the partial eclipse). The maximum reduction in VTEC at Hyderabad is $\sim 41 \%$ from PRN 14 at around 06:24 IST (i.e., after $2 \mathrm{~m}$ from the maximum obscuration and $\sim 56 \mathrm{~min}$ from the beginning of the partial eclipse). At Bangalore the reduction is $\sim 33 \%$ from PRN 31, which occurs at around 06:36 IST (i.e., after $15 \mathrm{~min}$ from the maximum obscuration and about $1 \mathrm{~h}$ and $7 \mathrm{~min}$ from the beginning of the partial eclipse). A reduction of $\sim 30 \%$ from PRN 14 at around 06:26 IST (i.e., after 5 min from the maximum obscuration or about $57 \mathrm{~min}$ from the beginning of the partial eclipse) is observed. Thus it is noted that the maximum reduction in VTEC at all four stations is found after 2-15 min from the maximum obscuration time. Reduction in ionospheric TEC for the annular eclipse of 3 October 2005, and dependence of TEC on latitude as well as longitude, was reported by Krankowski et al. (2008). Earlier studies showed a decrease in TEC after the beginning of the partial solar eclipse, and TEC reached a minimum value after a lapse of time varying between $30 \mathrm{~min}$ and $2 \mathrm{~h}$ from the time of maximum obscuration (Yeh et al., 1997; Huang et al., 1999; Jakowski et al., 2008; Krankowski et al., 2008). For the solar eclipse of 22 July 2009, Sharma et al. (2010) reported a significant decrease in electron density and TEC at Udaipur, Hyderabad and Bangalore stations. They have also reported that the reduction persisted up to $2 \mathrm{~h}$ past the last contact. Galav et al. (2010), for the annular solar eclipse of 15 January 2010, showed a reduction of $20 \%$ in the total electron content at Bangalore. The decreasing trends of the ionospheric electron density and total electron content have been reported for different solar eclipse from low latitudes (Chandra et al., 1980, 1981, 1997, 2007; Vyas et al., 1997; Yeh et al., 1997), but the importance of present study lies in the fact that comparable reductions in TEC have been observed at four places located on different latitudes and longitudes.

The ionization density and the total electron content in the ionosphere at any given altitude depend on various phenomena such as production and loss rates involving chemical reactions and transport phenomena involving diffusion and drifts. In the lower ionosphere (D, E, F1 regions), photoionization and recombination processes play a major role in the plasma maintenance, whereas the transport processes are important in the F2 layer and at higher altitudes. The solar eclipse affects production rate by reducing solar radiation and loss rate by affecting coefficients of different reactions that are temperature-dependent. Transport processes are also affected as they are temperature-sensitive. During a solar eclipse, there is sudden partial/full termination of solar radiation, which results in quick partial/full termination of photoionization. Loss processes are not stopped, and consequently reduction in the electron density and total electron content are observed from the start of solar eclipse at all four stations in the present case. The maximum depletion occurs just after the maximum obscuration time with a delay lying between 5 and $15 \mathrm{~min}$. This time delay may be attributed to the slower reaction of the transport process than the photoionization process (Chen et al., 1999). This is also evident from the fact that just after the time of the maximum obscuration, the recovery rate of TEC is larger than that after the termination of eclipse. It takes more than $2 \mathrm{~h}$ after the eclipse for the TEC to reach its normal value with a slower rate of recovery. For the same eclipse, Sharma et al. (2010) reported a time delay of $30 \mathrm{~min}$ from Udaipur station.

There is a sudden significant drop in temperature during the solar eclipse, which results in a decrease in plasma temperature. However, electron temperature drops more quickly than ions (Evans, 1965), leading to decreased ratio of electron-ion temperature and acceleration of downward diffusion of electrons from the topside ionosphere (Yeh et al., 1997). The electrons reaching the lower altitudes are lost through the recombination process. The huge $(\sim 48 \%)$ reduction of electron density above the F2 peak (Fig. 3) demonstrates the effectiveness of the downward diffusion process during the solar eclipse period. As the observing stations lie in the EIA zone, the electrodynamic $(\boldsymbol{E} \times \boldsymbol{B})$ drift and the equatorial fountain effect are operational in the plasma transport. Chen et al. (1999) discussed that the strength of the equatorial fountain effect is reduced during the eclipse period. However, we could not separate the contribution of different processes or make any comments about their individual contribution.

Different satellite links show varying degrees of maximum depletion in the total electron content at different locations. For example PRN 14 yields a larger percent of depletion at Varanasi and Hyderabad, whereas PRN 31 shows a larger percent of depletion at Kanpur and Bangalore. This may be understood in terms of satellite location and the link path covering the eclipse zone of varying solar obscuration.

The height profile of electron density over the Indian region during the eclipse period obtained from the constellation of COSMIC satellites shows a considerable decrease from 100 to $800 \mathrm{~km}$ altitude. This supports the observed reduction in the GPS-measured total electron content in the Indian sector. The maximum reduction for PRN 31 is 4.3, 5.23, 3.13 and 3.0 TECU respectively at Varanasi, Kanpur, Hyderabad and Bangalore. The same for PRN 14 is 5.3, 5.0, 3.0 and 2.5 TECU respectively. Thus we find comparable reduction at Varanasi and Kanpur, although Varanasi lies in the total obscuration path and Kanpur lies at the outer edge of the 
total obscuration path. The amount of reduction decreases as moving away from the total obscuration path. Sharma et al. (2010) reported a maximum reduction of about 5 TECU at Udaipur, where the maximum obscuration was $93.8 \%$. In other eclipse cases, a reduction ranging from 0.2 to 4 TECU has been reported (Afraimovich et al., 2002; Krankowski et al., 2008). Choudhary et al. (2011), for the solar eclipse of 15 January 2010, have reported a larger decrease in the VTEC at Hyderabad as compared to that for Bangalore and Trivandrum, whereas the obscuration at Hyderabad, Bangalore and Trivendrum was $67.5,77.1$ and $84.3 \%$ respectively. The VTEC at Trivendrum recovered to the mean value by 18:00 IST ( $\sim 2 \mathrm{~h}$ and $50 \mathrm{~min}$ after the eclipse), whereas at Hyderabad VTEC did not recover even up to 20:00 IST. This anomalous behavior of VTEC at Hyderabad may be due to electrodynamic effect induced by the eclipse, which affected plasma density of the region away from the eclipse path. For the same eclipse Kumar and Singh (2012) reported a larger reduction in VTEC at Varanasi as compared to Hyderabad and Bangalore, whereas the obscuration at Bangalore, Hyderabad and Varanasi was 84.5, 77.4 and $68.4 \%$ respectively. Thus we find significant reduction even in a solar eclipse, which occurred in the early morning hours just around the sunrise time.

The Fourier analysis of DTEC reflects the presence of several amplitude peaks of different periods. The dominant peaks correspond to waves with periods lying in the range $20-40$ and 40-60 min for Varanasi, 40-60 min for Kanpur, 80-110 min for Hyderabad and 70-100 min and 100$120 \mathrm{~min}$ for Bangalore. The results suggest that as the observing station is away from the total obscuration path, the wave period goes on increasing. The oscillating signature present in VTEC can be attributed to the ionospheric region because the largest contribution to VTEC comes from the $200-400 \mathrm{~km}$ altitude range. The sudden cooling of the atmosphere may cause generation of wavy structures (gravity waves) both in the lower atmosphere and in the thermosphere. The wave period increases as gravity waves move upwards. The observed period of waves during the solar eclipse of 11 August 1999 near the ground was $~ 9-12$ and $\sim 60 \mathrm{~min}$ in the ionosphere (Farges et al., 2003). Singh et al. (1989), analyzing data recorded at a station more than $500 \mathrm{~km}$ away from the totality zone, obtained a wave period lying in the range $10-40 \mathrm{~min}$ in the ionosphere. Zerefos et al. (2007), based on measurements at the troposphere, stratosphere and ionosphere, showed evidence supporting the hypothesis that the cooling of the ozone layer in the stratosphere by the Moon's shadow traveling at supersonic speed during the eclipse constitutes the source of gravity waves with periods of 30-40 min, which propagated both upwards and downwards. The wave periods reported in the present paper lie in the range reported by earlier workers (Altadill et al., 2001; Sauli et al., 2006). The variation in wave periods may be attributed to the complex nature of the wave generation mechanism during the eclipse and the propagation of waves from the source to the observation site.

\section{Summary}

The diurnal variation of VTEC during the total solar eclipse of 27 July 2009 at the four low-latitude stations spread between geographic latitude $12^{\circ} 58^{\prime} \mathrm{N}$ and $26^{\circ} 28^{\prime} \mathrm{N}$ shows significant reduction during the eclipse period and beyond. The maximum reduction occurs a few minutes $(2-15 \mathrm{~min})$ after the maximum obscuration time, which may be due to the involved timescale in photoionization and transport phenomena. The maximum reduction (PRN 14) is observed at Varanasi, which lies inside the total obscuration. The amount of reduction decreases as the percent obscuration decreases. However, for PRN 31, the maximum reduction is observed at Kanpur, which lies at the outer edge of the total obscuration. This result may be due to the satellite path relative to the solar eclipse obscuration. The recovery of VTEC to a normal value occurs first at those stations, which lie in the partial obscuration region with a smaller percent of obscuration as compared to full obscuration.

The vertical electron density profile shows significant reduction in electron density from 100 to $800 \mathrm{~km}$ altitude with a maximum of $48 \%$ decrease at $360 \mathrm{~km}$ altitude. The significant decrease at higher altitude causes longer recovery time to the normal value after the end of eclipse, because transport processes are slow compared to photoionization. The Fourier analysis of VTEC shows the presence of wavy structures having periods between 40 and $120 \mathrm{~min}$, which are attributed to the eclipse-induced cooling of the stratosphere/mesosphere.

Acknowledgements. Sanjay Kumar is thankful to Ram Sagar, Director ARIES for providing required facility. The work is partially supported by ISRO, Bangalore. We acknowledge the International GNSS Service (IGS) for providing us GPS data. My sincere thanks go to Onkar Dixit for providing GPS data of Kanpur, where the GPS facility is established under the MoES-sponsored project. Authors are grateful to the two anonymous reviewers for their constructive comments and suggestions that improved the manuscript.

Topical Editor K. Hosokawa thanks H. Chandra and one anonymous referee for their help in evaluating this paper. 


\section{References}

Afraimovich, E. L., Palamartchouk, K. S., Perevalova, N. P., Chemukhov, V. V., Lukhnev, A. V., and Zalutsky, V. T.: Ionospheric effects of the solar eclipse of March 9, 1997, as deduced from GPS data, Geophys. Res. Lett., 25, 465-468, 1998.

Afraimovich, E. L., Kosogorov, E. A., and Lesyuta, O. S.: Effects of the August 11, 1999 total solar eclipse as deduced from total electron content measurements at the GPS network, J. Atmos. Solar-Terr. Phys., 64, 1933-1941, 2002.

Altadill, D., Sole, J. G., and Apostolov, E. M.: Vertical structure of a gravity wave like oscillation in the ionosphere generated by the solar eclipse of August 11, 1999, J. Geophys. Res., 106, 2141921428, 2001.

Bagiya, M. S., Iyer, K. N., Joshi, H. P., Thampi, S. V., Tsugawa, T., Ravindran, S., Sridharan, R., and Pathan, B. M.: Lowlatitude ionospheric-thermospheric response to storm time electrodynamical coupling between high and low latitudes, J. Geophys. Res., 116, A01303, doi:10.1029/2010JA015845, 2011.

Chakrabarty, D. K., Shah, N. C., and Pandya, K. V.: Fluctuation in ozone column over Ahmedabad during the solar eclipse of 24 October 1995, Geophys. Res. Lett., 24, 3001-3003, 1997.

Chandra, H., Deshpande, M. R., Vyas, G. D., Sethia, G., Vats, H. O., Iyer, K. N., and Janve, A. V.: Ionospheric effects during February 1980 solar eclipse, B. Astron. Soc. India, 8, 145-148, 1980.

Chandra, H., Sethia, G., Vyas, G. D., Deshpande, M. R., and Vats, H. O.: Ionospheric effects of the total solar eclipse of 16 February 1980 observed over Ahmedabad, Indian J. Radio Space Phys., 10, 45-48, 1981.

Chandra, H., Vyas, G. D., and Sharma, S.: Ionospheric effects the total solar eclipse of 24 October 1995 over Ahmedabad, Indian J. Radio Space Phys., 26, 30-35, 1997.

Chandra, H., Sharma, S., Lele, P. D., Rajaram, G., and Hanchinal, A.: Ionospheric measurements during the total solar eclipse of 11 August 1999, Earth Planets Space, 59, 59-64, 2007.

Chen, A.-H., Yu, S.-B., and Xu, J.-S.: Ionospheric response to a Total Solar Eclipse Deduced by the GPS Beacon Observations, Wuhan University Journal of Natural Science, 4, 439-444, 1999.

Chimonas, G.: Internal gravity-wave motions induced in the Earth's atmosphere by a solar eclipse, J. Geophys. Res., 75, 5545-5551, 1970.

Chimonas, G.: Lamb waves generated by the 1970 solar eclipse, Planet. Space Sci., 21, 1843-1854, 1973.

Chimonas, G. and Hines, C. O.: Atmospheric Gravity waves induced by a solar eclipse, J. Geophys. Res., 75, 5545-5551, 1970.

Chimonas, G. and Hines, C. O.: Atmospheric Gravity waves induced by a solar eclipse, 2, J. Geophys. Res., 76, 7003-7005, 1971.

Choudhary, R. K., St.-Maurice, J.-P., Ambili, K. M., Sunda, S., and Pathan, B. M.: The impact of January 15, 2010, annular solar eclipse on the equatorial and low-latitude ionospheric densities, J. geophys. Res., 116, A09309, doi:10.1029/2011JA016504, 2011.

DasGupta, A., Mitra, A., Das, S. K., and Sen, S. K.: Ionospheric electron content observations during the total solar eclipse of February 16, 1980, J. Atmos. Terr. Phys., 43, 135-137, 1981.

Davies, K. and Hartmann, G. K.: Studying the ionosphere with Global Positioning System, Radio Sci., 32, 1695-1703, 1997.
Ding, F., Wan, W., Ning, B., Liu, L., Le, H., Xu, G., Wang, M., Li, G., Chen, Y., Ren, Z., Xiong, B., Hu, L., Yue, X., Zhao, B., Li, F., and Yang, M.: GPS-TEC response to the 22 July 2009 total solar eclipse in East Asia, J. Geophys. Res., 115, A07308, doi:10.1029/2009JA015113, 2010.

Evans, J. V.: An F Region Eclipse. J. Geophys. Res., 70, 131-142, 1965.

Farges, T., Pichon, A. Le Blanc, E., Perez, S., and Alcoverro, B.: Response of the lower atmosphere and the ionosphere to the eclipse of August 11, 1999, J. Atmos. Solar-Terr. Phys., 65, 717-726, 2003.

Founda, D., Melas, D., Lykoudis, S., Lisaridis, I., Gerasopoulos, E., Kouvarakis, G., Petrakis, M., and Zerefos, C.: The effect of the total solar eclipse of 29 March 2006 on meteorological variables in Greece, Atmos. Chem. Phys., 7, 5543-5553, doi:10.5194/acp7-5543-2007, 2007.

Fritts, D. C. and Luo, Z.: Gravity wave forcing in the middle atmosphere due to reduced ozone heating during a solar eclipse, J. Geophys. Res., 98, 3011-3021, 1993.

Galav, P., Sharma, S., and Pandey, R.: Total electron content in peninsular India during the eclipse of 15 January 2010, Curr. Sci., 99, 731-732, 2010.

Galav, P., Sharma, S., and Pandey, R.: Study of simultaneous penetration of electric fields and variation of total electron content in the day and night sectors during the geomagnetic storm of 23 May 2002, J. Geophys. Res., 116, A12324, doi:10.1029/2011JA017002, 2011.

Huang, C. R., Liu, C. H., Yeh, K. C., Lin, K. H., Tsai, W. H., Yeh, H. C., and Liu, J. Y.: A study of tomographically reconstructed ionospheric images during a solar eclipse, J. Geophys. Res., 104, 79-94, 1999.

Jakowski, N., Stankov, S. M., Wilken, V., Borries, C., Atadill, D., Chum, J., Buresova, D., Boska, J., Sauli, P., Hruska, F., and Cander, L. R.: Ionospheric behaviour over Europe during the solar eclipse of 3 October 2005, J. Atmos. Solar-Terr. Phys., 70, 836853, 2008.

Jayakrishnan, P. R., Babu, C. A., and Sivaprasad, P.: Drastic variation in the surface boundary layer parameters over Cochin, during the Annular Solar Eclipse: Analysis using sonic anemometer data, J. Atmos. Solar-Terr. Phys., 94, 49-53, 2013.

Krankowski, A., Shagimuratov, I. I., Baran, L. W., and Yakimova, G. A.: The effect of total solar eclipse of October 3, 2005, on the total electron content over Europe, Adv. Space Res., 41, 628638, 2008.

Kumar, S. S. and Rengaiyan, R.: Influence of solar eclipse on seawater, Natural Science, 3, 69-74, 2011.

Kumar, S. and Singh, A. K.: GPS derived ionospheric TEC response to geomagnetic storm on 24 August 2005 at Indian low latitude stations, Adv, Space Res., 47, 710-717, 2011.

Kumar, S. and Singh, A. K.: Changes in Total Electron Content (TEC) during the Annular Solar Eclipse of 15 January 2010, Adv. Space. Res., 49, 75-82, 2012.

Langley, R., Fedrizzi, M., Paula. E., Santos, M., and Komjathy, A.: Mapping the low latitude ionosphere with GPS, GPS World, 13, 41-46, 2002.

Le, H., Liu, L., Yue, X., and Wan, W.: The ionospheric responses to the 11 August 1999 solar eclipse: observations and modeling, Ann. Geophys., 26, 107-116, doi:10.5194/angeo-26-107-2008, 2008. 
Le, H., Liu, L., Ding, F., Ren, Z., Chen, Y., Wan, W., Ning, B., Xu, G., Wang, M., Li, G., Xiong, Bo, and Hu, L.: Observations and modeling of the ionospheric behaviors over the east Asia zone during the 22 July 2009 solar eclipse, J. Geophys. Res., 115, A10313, doi:10.1029/2010JA015609, 2010.

Liu, J. Y., Hassio, C. C., Tsai, L. C., Liu, C. H., Kuo, F. S., Lue, H. Y., and Huang, C. M.: Vertical phase and group velocities of internal gravity waves from ionograms during the solar eclipse of 24 October 1995, J. Atmos. Sol-Terr. Phys., 60, 1679-1686, 1998.

Muller-Wodarg, I. C. F., Aylward, A. D., and Lockwood, M.: Effects of a mid-latitude solar eclipse on the thermosphere and ionosphere-a modeling study, Geophys. Res. Lett., 25, 37873790, 1998.

Mannucci, A. J., Wilson, B. D., and Ewards, C. D.: A new method for monitoring the Earth's ionosphere total electron content using the GPS global network, Proc. of ION GPS-93, Inst. of Navigation, 1323-1332, 1993.

Paul, A., Das, T., Ray, S., Das, A., Bhowmick, D., and DasGupta, A.: Response of the equatorial ionosphere to the total solar eclipse of 22 July 2009 and annular eclipse of 15 January 2010 as observed from a network of stations situated in the Indian longitude sector, Ann. Geophys., 29, 1955-1965, doi:10.5194/angeo29-1955-2011, 2011.

Rama Rao, P. V. S., Gopi Krishna, S., Niranjan, K., and Prasad, D. S. V. V. D.: Temporal and spatial variations in TEC using simultaneous measurements from the Indian GPS network of receivers during the low solar activity period of 2004-2005, Ann. Geophys., 24, 3279-3292, doi:10.5194/angeo-24-3279-2006, 2006.

Ridley, E. C., Dickinson, R. E., Roble, R. G., and Rees, M. H.: Thermospheric response to the June 11, 1983, solar eclipse, J. Geophys. Res., 89, 7583-7588, 1984.

Roble, R. G., Emery, B. A., and Ridley, E. C.: Ionospehric and Thermospheric response over Millstone Hill to the May 30, 1984, annular solar eclipse, J. Geophys. Res., 91, 1661-1670, 1986.

Salah, J. E., Oliver, W. L., Foster, J. C., and Holt, J. M.: Observations of the May 30, 1984, Annular Solar Eclipse at Millstone Hill, J. Geophys. Res., 91, 1651-1660, 1986.

Sauli, P., Abry, P., Boska, J., and Duchayne, L.: Wavelet characterization of ionospheric acoustic and gravity waves occurring during the solar eclipse of August 11, 1999, J. Atmos. Solar-Terr. Phys., 68, 586-598, 2006.

Sharma, S., Dashora, N., Galav, P., and Pandey, R.: Total solar eclipse of July 22, 2009: Its impact on the total electron content and ionospheric electron density in the Indian zone, J. Atmos. Solar-Terr. Phys., 72, 1387-1392, 2010.

Singh, L., Tyagi, T. R., Somayaulu, Y. V., Vijaykumar, P. N., Dabas, R. S., Loganadham, B., Ramakrishna, S., Rama Rao, P. V. S., Dasgupta, A., Naneeth, G., Klobuchar, J. A., and Hartmann, G. K.: A multi-station satellite radiobeacon study o ionospheric variations during solar eclipses, J. Atmos. Solar-Terr. Phys., 51, 271-278, 1989.
Sridharan, R., Devasia, C. V., Jyoti, N., Tiwari, Diwakar, Viswanathan, K. S., and Subbarao, K. S. V.: Effects of solar eclipse on the electrodynamical processes of the equatorial ionosphere: a case study during 11 August 1999 dusk time total solar eclipse over India, Ann. Geophys., 20, 1977-1985, doi:10.5194/angeo-20-1977-2002, 2002.

St-Maurice, J.-P., Ambili, K. M., and Choudhary, R. K.: Local electro-dynamics of of the solar eclipse at the magnetic equator in the early afternoon hours, Geophys. Res. Lett., 38, L04102, doi:10.1029/2010GL046085, 2011.

Tomás, A. T., Lühr, H., Förster, M., Rentz, S., and Rother, M.: Observations of the low-latitude solar eclipse on 8 April 2005 by CHAMP, J. Geophys. Res., 112, A06303, doi:10.1029/2006JA012168, 2007.

Tyagi, T. R., Singh, L., Vijaykumar, P. N., Somayajulu, Y. V., Loganadham, B., and Yellaiah, G.: Satellite Radio Beacon study of the ionospheric variations at Hyderabad during the total solar eclipse of February 16, 1980, Bull. Astro. Soc. India, 8, 69-72, 1980.

Venkatesh, K., Rama Rao, P. V. S., Saranya, P. L., Prasad, D. S. V. V. D., and Niranjan, K.: Vertical electron density and topside effective scale height (HT) variations over the Indian equatorial and low latitude stations, Ann. Geophys., 29, 1861-1872, doi:10.5194/angeo-29-1861-2011, 2011.

Vyas, G. D., Chandra, H., and Sharma, S.: Ionospheric effects of the total solar eclipse of 24 October 1995 over Ahmedabad, Adv. Space Res., 20, 1293-1296, 1997.

Yeh, K. C., Yu, D. C., Lin, K. H., Huang, C. R., Tsai, W. H., Liu, J. Y., Xu, J. S., Igarashi, K., Xu, C., and Nam, V. H.: Ionospheric response to a solar eclipse in the equatorial anomaly region, Terr. Atmos. Oceanic Sci., 8, 165-178, 1997.

Zerefos, C. S., Balis, D. S., Meleti, C., Bais, A. F., Tourpali, K., Kourtidis, K., Vanicek, K., Cappelani, F., Kaminski, U., Colombo, T., Stubi, R., Manea, L., Formenti, P. and Andreae, M.O.: Changes in surface solar UV irradiances and total ozone during the solar eclipse of 11 August, 1999, J. Geophys. Res., 105, 26463-26473, 2000.

Zerefos, C. S., Gerasopoulos, E., Tsagouri, I., Psiloglou, B. E., Belehaki, A., Herekakis, T., Bais, A., Kazadzis, S., Eleftheratos, C., Kalivitis, N., and Mihalopoulos, N.: Evidence of gravity waves into the atmosphere during the March 2006 total solar eclipse, Atmos. Chem. Phys., 7, 4943-4951, doi:10.5194/acp-74943-2007, 2007.

Zhang, S.-R., Holt, J. M., Zalucha, A. M., and Amory-Mazaudier, C.: Midlatitude ionospheric plasma temperature climatology and empirical model based on Saint Santin incoherent scatter radar data from 1966 to 1987, J. Geophys. Res., 109, A11311, doi:10.1029/2004JA010709, 2004. 